\title{
THE ETHICAL ASSESSMENT OF TECHNOLOGY: THEORETICAL ISSUES AND METHODOLOGICAL DIFFICULTIES
}

\author{
Andrei JOSAN ${ }^{a^{*}}$ \\ ${ }^{a}$ Bucharest University of Economic Studies, Romania
}

\begin{abstract}
The main thesis of our research is that the increasingly rapid advance of technology in the contemporary world has led to the emergence of unprecedented theoretical and methodological problems regarding the moral evaluation of new technologies, given that technological progress has increasingly overtaken the ability of society, governments and corporations to anticipate the possible ethical consequences generated by the introduction of new technologies. New technologies generate extremely many challenges to society, organizations, the business world and individuals taken separately in conditions where the rate of change is increasingly rapid and the complexity of the technological environment is increasing in recent decades during which a transition has taken place from a world characterized by industrial technology to one dominated by information technology and biotechnology. The objective of the research is to highlight a number of potential theoretical and methodological problems that make it extremely difficult to assess from an ethical perspective new emerging technology with the intention of helping to find answers to a number of fundamental questions, such as: How can we morally assess the development of technologies when they have an open horizon and involve uncertainty and lack of control? How and who should control the new emerging technologies? How will new technologies materialize and what will be their impact and influence?
\end{abstract}

KEYWORDS: disruptive technologies, emerging technologies, ethics, technology.

DOI: 10.24818/IMC/2021/05.11

\section{INTRODUCTION}

Technology can be defined as the totality of the means used to provide the objects necessary for human sustenance and comfort. Technology is also a scientific method used in achieving a practical purpose (Webster's Ninth New Collegiate Dictionary, 1983, p.1211). Technology encompasses all the ways in which by using tools, techniques, machines, inventions and scientific discoveries people satisfy their needs and desires. All this, taken together, made the work easier and more productive (The World Book Encyclopedia, 1988, p.76). A commonly used concept refers to the technological environment, which is the total set of improvements generated by technology (or progress) that take place in society. These include new products, processes, materials and scientific advances, both in the theoretical and applicative sense. The enormous benefits of technology, but also the multiple problems created by it, have been quantified among others, by Friedel (Friedel, 2007) and, more recently, by Harari (Harari, 2014, 2016), authors who have brought up the classic dilemma regarding the intrinsic nature of technology, namely that of being a "two edge-sword", technological progress having the potential to be both a "liberating" force, as well as a "destructive" one of society. According to Naisbitt, Naisbitt and Phillips, in the best case, technology will support

\footnotetext{
* Corresponding author. E-mail address: andrei.josan@rei.ase.ro
} 
and improve people's lives, and in the worst case it will alienate, distort and destroy it (Naisbitt, Naisbitt \& Phillips, 1999).

In the course of history, technology has positively influenced society in four main ways: (1) it has amplified the production of goods and services; (2) reduced the amount of work required for the production of goods and services; (3) the technology has not only made it possible to increase production by using less human labor, but has also made the work easier and safer; (4) as a direct result of this "labor-saving technology" the standard of living has continuously increased. On the other hand, the technologies also had negative effects, which were often unanticipated before being deployed, because, in general, technologies were and continue to be introduced without considering the potential possible negative side effects and without taking into account the potential risks or moral problems generated by those technologies. There are four major negative side effects induced by technology: (1) environmental pollution; (2) depletion of natural resources; (3) technological unemployment; (4) the creation of unsatisfactory jobs. New technologies are causing many challenges to society, organizations, the business world and individuals taken separately as the rate of change is increasingly rapid and the complexity of the technological environment is increasing in recent decades, during which there has been a transition from "a world characterized by industrial technology to one dominated by information technology and biotechnology" (Carroll \& Buchholtz, 2009, p.350).

Technology has an extremely large influence on society, technological innovations having a major impact on people's perception of themselves, the world, human relationships and relationships with other objects. Technology is constantly changing the way people live, creating new entities software, nanoparticles, internet, biotechnology (Hockfield, 2019), changing the scale of activities (Big Data) and generating new types of knowledge (for example, about the human genome and various maladies). The challenges posed by technology require the development of an ethic of proactive technology that does not wait for the emergence of moral problems induced by technology, but tries to identify and evaluate the potential moral problems caused by technological development from the very early stages of the introduction of new technologies.

\section{THE MORAL DIMENSION OF TECHNOLOGY}

Defined briefly and in general, the ethics of technology is the ethics of man-made objects. To underline the importance of the ethical dimension of technology, it is important to understand how obsessed and "intoxicated" technology has become, contemporary society that has really evolved from "a technologically comfortable place to a technologically intoxicated zone" (Naisbitt, Naisbitt \& Phillips, 2001, p.10). In Carroll and Buchholtz's interpretation, the six symptoms of societal intoxication with technology are (1) favoring the quick solution, (2) the simultaneous adulation and fear of technology, (3) blurring the distinction between what is real and what is false, between authentic and simulated, (4) accepting violence as something normal, (5) equating technology with gadgets, and (6) a distant and withdrawn way of life. (Carroll \& Buchholtz, 2009, p.354). The consumer society, based on the Band-Aid type culture that favors rapid technological solutions in all spheres of life from nutrition to religion in the complex contemporary world in which the modern man seduced by the promises of technology perceives a recurrent abyss for who's overcoming constantly seeks something material and/or immaterial to simplify his life and relieve himself of stress, is, however, finally a culture devoid of consistency. On the other hand, in our dual relationship with technology we move from one extreme to another, from adulation to fear, accepting technology fearing that we will lagging behind competitors or co-workers and friends, but after that we feel frustrated and disturbed when it does not work. Moreover, we blur the distinction between what is real and what is false, and between what is authentic and what is simulated. In contemporary society, technology has made it possible to pack violence in the form of merchandise, frequently provided through television, movies, computer games and other media channels, thus 
being "normalized". Moreover, as the affluence makes its effects felt, leisure tends towards fun/distraction being a way of occupying time in a world dominated by consumerist technology in which relaxation is often received passively; the problem is that real relaxation is not, however, based on the desire to consume, it requires peace of mind, patience and attention. The promises of technology are seductive, but in reality, they distance and distract us: the internet, mobile phones and wireless technologies promise to connect us, but when is this connection right and when is a distraction? The right treatment of this intoxication is to find a balance, in the sense that we must embrace the technologies that allow us to preserve the humanity within us and reject intrusive and dehumanizing technologies (Carroll \& Buchholtz, 2009, p.354).

Any foray into the ethics of technology should determine what both technology professionals and ordinary users need to do when faced with ethical issues arising from new or existing technologies. The main task of any ethics of technology is to identify the morally right courses of action when developing, using or modifying technological artifacts. From this perspective, the ethics of technology is an area of applied ethics, as important as medical ethics, business ethics, environmental ethics and military ethics (Peterson, 2017, p.3). The main purpose of a technology ethic is to determine which ethical values and norms and which other moral properties are embedded in technological artifacts as artifacts in themselves (Latour, 2009; Verbeek, 2011). Peterson articulated and defended five moral principles deemed necessary and sufficient by combining to analyze ethical issues related to new or existing technologies within the methodological framework of analytical philosophy as defined by Bertrand Russell, in whose vision "a hallmark of analytic philosophy is its incorporation of mathematics and its development of a powerful logical technique" (Russell, 1945, p.845). The starting point of the "geometric" method developed by Peterson is that "for each domain-specific principle there exists one or several paradigm cases to which that principle applies" (Peterson, 2017, p.14). The five principles proposed by Peterson are as follows: (1) The Cost-Benefit Principle; (2) The Precautionary Principle; (3) The Sustainability Principle; (4) The Autonomy Principle; (5) The Fairness Principle (Peterson, 2017, p.14). First of all, according to Peterson a technological intervention to which the cost-benefit principle applies is morally correct only if the net surplus of benefits over costs for all those affected is at least as high as that of any alternative. Secondly, a technological intervention to which the precautionary principle applies is only morally correct if reasonable preventive measures are taken to protect against uncertain but need to be taken into account threats. Thirdly, a technological intervention to which the principle of sustainability applies is only morally correct if it does not lead to a significant long-term reduction in natural, social or economic resources. Fourthly, a technological intervention to which the principle of autonomy applies is morally correct only if it does not reduce the independence, self-government or freedom of the people affected by it, and last but not least, a technological intervention to which the principle of fairness applies is morally correct only if it does not lead to incorrect inequalities between the people affected by it (Peterson, 2017, p.14). In Peterson's view, each of the five principles is meant to guide our actions only in a small number of cases, as they do not apply to all cases. Each principle assumes at least one necessary condition for a new technology to be considered morally correct, but none of the principles taken individually is sufficient to determine on its own the "moral correctness" of that technological innovation.

\section{THEORETICAL ISSUES AND METHODOLOGICAL DIFFICULTIES}

In the field of technology ethics, two key issues are crucial. Firstly, there is the problem of technological determinism, which refers to the imperative that "what can be developed will be developed" and, secondly, of "the ethical lag", a phenomenon that occurs when the speed of technological change far exceeds that of ethical development. The difficulty of ethical assessment of technology is also determined by the problem of complexity and uncertainty generated by the 
introduction of any new technology. Technology is a multifaceted concept. According to Mitcham, technology is a quadruple activity. First of all, technology is an "object", technological artifacts such as tools, of things manufactured in general, being the ones that come to mind first when we think of technology: "Technology as object is the most immediate, not to say the simplest mode in which technology is found manifest, and it can include all humanly fabricated material artifacts whose function depends on a specific materiality as such" (Mitcham, 1994, p.161). Second, technology means "technological knowledge" in the fields of science, engineering and social sciences, it is the knowledge of the type "how to" and of the type" know-how to understand technology" and the ability to apply this science in technological artifacts. Third, the technology not only includes technological artifacts and technological knowledge, but also refers to "the technological activity of making and using technological artefacts": "Technology as activity is that pivotal event in which knowledge and volition unite to bring artifacts into existence or to use them" (Mitcham, 1994, p.209). In this procedural sense, technology refers to the problem-solving process, design, research and development, inventions and innovations in technological development. Fourthly, technology is "volition", in the sense that technology is a force and/or a social construction, in this sense technology having the connotation and being perceived "as one does or wants with technology and, moreover, how it influences human beings and their behavior" (Sollie \& Duwell, 2009, p.2).

Referring to the issue of the complexity of technological innovations, a common feature of technologies is that when they are developed most of the time, we are ignorant and we are not sure about the possible applications and consequences of those technologies, a situation that results from the multifaceted interactions in a heterogeneous field of scientific, political, moral, social and economic forces. Under these circumstances, the impact, subsequent consequences and ethical issues are often not apparent from the outset. Moreover, these future consequences may be unanticipated, unintentional and unforeseen, which gives rise to a dilemma, "the control dilemma", signaled by Collingridge: "Attempting to control a technology is difficult, and nor rarely impossible, because during its early stages, when it can be controlled, not enough can be known about its harmful social consequences to warrant controlling its development; but by the time these consequences are apparent, control has become costly and slow" (Collingridge, 1980, p.19). The "control dilemma" highlights two problems that arise in the process of assessing the impact of the technology: "the prediction horn" and "the control horn". "The prediction horn of the dilemma" refers to the fact that although in the early stages of the design of new technologies their control is, in principle, quite possible, it is actually unimportant due to the lack of relevant information and the underlying inability to predict the future. While new technologies are being developed most of the time possible adverse consequences and side effects that can widely affect society are ignored; subsequently, after a long and complex process, technologies are introduced and adopted by society and thus there are a variety of tools to assess the impact of those technologies on society. Thus, "the control horn of the dilemma" is connected to the process of evaluation and control of stabilized technologies. At this stage, that technology is in use, and its consequences and impact become apparent. Given that in the design phase it can be considered illogical to talk about the control of that technology due to the lack of information relevant to the evaluation, at the stage of introducing and stabilizing the relevant information becomes available, but at this point, the adjustments are expensive and slow. This situation explains the need to find an answer to a number of questions that also include an ethical component: How and who should control emerging technologies? How will new technologies materialize and what will be their impact and influence? How will new technologies transform people's practical activities? How can we morally assess the development of technologies when they have an open horizon, involve uncertainty and lack of control?

The uncertainty generated by technological development is closely related to one of the most striking features of the technology, namely what Jim Moor called "logical malleability" (Moor, 1985). Technological artifacts are "logically malleable" in the sense that they can be modeled to do 
any activity that can be characterized in terms of logical operations. According to Moor, computers are generic devices, "general-purpose machines" that can be used in various ways. The concept of logical malleability can be extended to all new technologies in the sense that they can be used in new and unforeseen ways and areas for which there are frequently no policies and procedures for controlling and assessing their effects. A relatively similar concept was used by Ihte according to which technologies are "multistable" (Ihte, 2002, p.106) because they can be used for a variety of purposes and, consequently, can be used for a variety of purposes and, consequently, can be used for a variety of purposes and, consequently, can be used "conceived of differently according to specific contexts of application". Technologies can replace and simplify existing devices, processes and actions, but they can also be used in unforeseen ways whose impact is difficult to predict. This situation has led some authors, including Brey, to state that the development of technologies is "morally non-transparent or opaque by nature" (Brey, 2001, pp.52-53). Many of the societal consequences of complex new technologies are initially unidentified yet because they are invisible or not yet obvious. The best example is represented by mobile phones and gadgets through which we are monitored and our data is collected (Zuboff, 2019).

Although, in general, the technology has been considered to be morally neutral, many technological artifacts have a false neutrality and are not in reality morally neutral. For example, search engines developed to facilitate the user experience have algorithms in the background that are far from morally neutral. The uncertainty regarding the future consequences caused by the application of new technologies is also amplified by their strong and relatively rapid impact on the contemporary society, which, paradoxically, on the one hand, is impregnated and even intoxicated by technology and, on the other, is devoid of a mature and well-endowed technology ethics from a theoretical and methodological point of view. The cause of this methodological underdevelopment of technology ethics is the complex, dynamic and uncertain nature of an unprecedented contemporary technological revolution that has greatly amplified the problem of the "ethical lag".

In recent years, emerging technologies and those with disruptive potential have become a major subject of study of technoethics, a field that has increasingly focused its attention on the early stages of development of these technologies that have the potential to radically change society in ways that are extremely difficult to predict. Although the field of technology ethics is a relatively new one still at the stage of conceptual and theoretical clarifications, several specific approaches have been outlined within it and a number of methods have been developed through which technoethics tries to "solve" the main problem it faces, namely the problem of uncertainty regarding future technological artifacts, their potential uses and the resulting consequences as a result of the emergence of new emerging and disruptive technologies (Sollie, 2007).

A thorough understanding of the ethics of emerging and disruptive technologies requires as a first step a clear definition of these concepts. Emerging technologies are those technologies that are new, innovative and still in development and that have a potentially large-scale impact on the economy and society. These technologies are new in that they introduce and use new concepts, methods and techniques that cannot be subsumed to existing technologies. Also, these technologies are innovative in the sense that they promise new and potentially superior solutions to existing problems. They are still in development at a time when these technologies are still largely in the promise stage. No products or applications have yet emerged, at least not widely and only a few or none still has widespread applicability in the market. A main feature, however, is that these technologies are expected to have a major social and economic impact and generate consistent incomes, create a significant number of jobs and have the potential to affect and transform one or more important social or economic areas, such as, for example, transport, education, the retail industry, health systems or the military sector. Emerging technologies are technologies still in the development stage, not yet totally "entrenched" in society. Although technological innovation is not a simple linear process, it involves going through distinct stages that usually begin with the stage of research and investigation of new phenomena, ideas, techniques or architectures, followed by the 
stages of development, production, marketing and diffusion at the level of society. A technology that has completely gone through all these stages is an "entrenched technology" being associated with the development of products, processes, procedures and techniques that are widely used in society, that have familiar uses and have a known impact on society. Even though new products based on this type of technology may still emerge, they are nothing more than incremental improvements to existing products and do not involve radical innovations. Examples of "entrenched technology" include technologies in industries such as automotive, satellites, radio, polymers, information technology and nuclear technology. On the other hand, emerging technologies are entirely or largely in the R\&D stage and have not yet generated massive changes at the socioeconomic level. To become "entrenched technologies" requires further research, new techniques and new innovative approaches and/or new methods of combining them with other technologies in order for new products and applications to have a significant impact. Currently, emerging technologies include nanotechnology, synthetic biology, robots, augmented reality, intelligent materials, and "the Internet of Things".

Another relevant distinction is between stand-alone technologies and enabling technologies. Enabling technologies are those technologies that facilitate and/or provide cross-sectoral innovations for a wide range of products, industrial sectors and social fields. They combine with a large number of other technologies and thus develop innovative products and services. These technologies include steam engine, glassmaking technology, integrated circuits, thermal energy storage technologies, genetic engineering and nanotechnology. In addition, there are a number of enabling technologies specific to specific industries or industrial sectors, such as technologies for smart device services, for personalized medicine or for sustainable architecture. Stand-alone technologies, by contrast, are those technologies that offer specific products or services, with an applicability sometimes limited to a single industry or field. Examples of stand-alone technologies are quartz technology, ballistic missile technology, penicillin (Brey, 2017, p.177).

Another fundamental distinction is that between emerging and disruptive technologies. The term disruptive refers to an interruption or a disturbing of an orderly progression in the evolution of an event, process or activity and may involve the occurrence of a drastic structural alteration and/or the induction of confusion or causing disorder or discontinuity. Unlike the disruptive term, the term emergent refers to the emergence or existence and becoming of a process, phenomenon, artifact or activity that gradually become apparent after a period of relative obscurity. While an emerging technology can at some point turn into a disruptive one, sometimes its disruptive potential may not be recognized in the initial stages of its introduction. Given that new technologies are being introduced at an increasingly accelerated pace in all fields, in many cases, its disruptive potential is not apparent from the beginning, but only after it is applied on its own or in innovative combinations with other technologies. In other cases, however, a disruptive technology can really be the result of a scientific or technological breakthrough. Some of these technologies are specific and address a market niche, while others have the potential to be applied in a wide range of largescale fields. Disruptive technology can change the status quo to such an extent that it can cause the destruction, abandonment or fundamental transformation of existing infrastructure. In the light of this distinction, three fundamental questions about emerging technologies need to be answered: Which emerging technologies can be considered as having a latent disruptive potential? In which sector, region or application will that emerging technology be disruptive? What is the time horizon designed to implement that technology?

A scientific breakthrough can have more than a unique disruptive impact and can lead to a series of multiple disruptive consequences, as was the case with the discovery of the electron (1879) that led to the development of new technologies whose disruptive potential has progressively increased and has caused massive long-lasting changes on a large scale: transistors, integrated circuits and microprocessors are the direct result of these scientific and technological breakthroughs. Examples of technologies that had as their main purpose and effect the surprise of competitors or enemies are 
the appearance of the English bow (the British longbow), the Japanese long-range torpedo (the Japanese Long Lance Torpedo, Type 93, Sanso gyorai), the atomic bomb, the global positioning system (GPS), the appearance of the telephone (Bell), the appearance of the telephone (Bell), business computers (UNIVAC and IBM), of mobile phones (Motorola), genetic recombination technologies (Genentech), the advent of Google (PageRank) and iPod (Apple). In other cases, progress is determined by the innovative application of existing technologies, as was the case with social networks (Facebook, MySpace, Instagram, LinkedIn), improvised explosive devices (IEDs) and portable devices (such as Ipod and Ipad). Also, some technologies may remain just some curiosities that will not be launched outside the laboratories in which they were developed, others will cause fundamental changes, and some will be somewhere between these extremes and therefore, it is extremely important in analyzing their potential to understand the relevance and extent of dissemination (the scale of dissemination) of those technologies to ensure that they have a truly disruptive potential. In terms of the scale of dissemination, a high-dissemination technology is a technology that can be easily replicated with minimal investment in infrastructure, as is the case with a new algorithm for search engines or a new encryption code, which can be relatively easy to replicate by copying from one computer to another and by minimal investment in additional storage capacities and in servers. A low-dissemination technology is a technology that can only be replicated through significant investments in infrastructure, as is the case with semiconductor technologies or solar panels, which are created in large industrial complexes and which require massive capital investment. However, these distinctions do not apply to technologies that address niche markets as is the case, for example, flexible solar cells for professional climbers and the military. Also, weapons of mass destruction fall into this category, as is the case with biological agents that can affect a region, a city or an entire continent. In these situations, even if dissemination is limited, technology can have an oversized impact compared to the scale of its dissemination at the level of society.

Until the 1970s, technological innovation tended to come from a limited number of laboratories under the control of government or corporations and from a limited number of techno-clusters, geographical concentrations of organizations and businesses operating in the same fields with the aim of increasing productivity. The concept of techno-cluster, with its variations, industrial clusters (industry cluster), business clusters, competitive cluster or Porterian cluster was introduced and popularized by Porter (Porter, 1990). In recent decades, however, the number of techno-clusters and laboratories has grown at an increasingly accelerated pace, and as new technologies have been developed more and more rapidly, the need to monitor emerging technologies with a potentially disruptive impact that can trigger unexpected changes at national, regional or even cause changes in the balance of power at global level, it has worsened. The value and usefulness of monitoring/predicting technology (technology forecasting) lies not primarily in the ability to accurately predict the future but, rather, in the potential to minimize the surprises that may arise from the advent of disruptive technologies. Monitoring and forecasting technology involves: (1) defining and searching for key elements that either inhibit or facilitate new disruptive technologies; (2) assessing the potential disruptive impact of that technology; (3) posits potential future alternatives and, last but not least, (4) involves supporting the decision-making process by raising awareness, over an extended time horizon, of the existence of that disruptive potential of a given technology (Committee on Forecasting Future Disruptive Technologies, 2010, p.2).

All forecasting techniques and methods, regardless of the field, depend to some extent on historical data and that is why they tend to overestimate and privilege an evolutionary, linear perspective of innovation and therefore, there is a risk that this type of forecasting methods will be vulnerable when rapid, nonlinear and surprising developments of technology occur emerging mouths. For this reason, a methodology capable of predicting disruptive technologies should overcome this evolutionary bias and thus be able to identify unprecedented changes, given that a disruptive event often happens unexpectedly, abruptly and with a random frequency, which explains why prediction 
is so difficult by using an evolutionary approach. In order for the forecasting of disruptive technologies to be effective, it is necessary to develop new forecasting methods that include the appeal to chaos theory, artificial neural networks, advanced simulations, social networks, alternative reality games, and so on. The field of technology forecasting is a relatively new one, being initiated by research carried out by THE RAND Corporation in the years immediately following the Second World War. Among the first methods used to forecast technological development was the Delphi method, a method based on a process of collecting collective expert opinions on the trends and likely impact of the technologies analyzed; other methods developed at this early stage since the 1950s were gaming and planned alternative scenarios (gaming and scenario planning), all these methods along with others much more quantitatively still being used today.

In general, the forecasting methods widely used today can be divided into four categories: (1) intuitive methods (judgmental or intuitive methods); (2) extrapolation and trend analysis; (3) models; (4) and scenarios and simulations. With the strong development of computational platforms and the massive increase in the massive amount of information stored electronically in databases, there has been an increase in the use of quantitative methods in the process of forecasting technology. Among the most effective methods of forecasting disruptive technologies are TechCast, Delta Scan and X2 (whose name was changed in 2009 to Signtific: Forecasting Future Disruptions in Science and Technology), forecasting systems with architectures that are extremely well-built and are commonly used by researchers and governments (TechCast and X2 are used by the American government, while Delta Scan was developed for the British government): (1) TechCast, introduced in 1998 is based on a voluntary self-selection of experts examining technological advances on an ad hoc basis, among the system's strengths being persistence, quantification of forecasts and ease of use; (2) Delta Scan, introduced in 2005, is part of the UK's United Kingdom Horizon Scanning Centre system, which aims to become a persistent system; (3) X2/ Signtific: Forecasting Future Disruptions in Science and Technology is a persistent system with a new architecture and integrating multiple forecasting techniques (Delphi method, alternative reality gaming, and expert sourcing) within a new architecture (Committee on Forecasting Future Disruptive Technologies, 2010, p.2).

In the last two decades, five distinct types of methodological approaches for the moral evaluation of new emerging technologies have emerged in a context in which the ethics of emerging technologies have begun to position itself more and more precisely within the broader framework of quantitative and qualitative approaches to assessing the impact of new technologies on society such as: technology assessment and evaluation (TA), futures studies, impact assessment, risk-benefit analysis, cost-benefit analysis, cost-utility analysis, cost-utility analysis, cost-utility analysis and approaches focused on cost-benefit analysis deliberative decision-making processes, on the degree of stakeholder involvement or on the impact on political systems. Many of the approaches to the ethics of technology are a combination of purely moral and non-moral perspectives.

Generic approaches are focused on the general characteristics of emerging technologies, characteristics that pose ethical questions, independently of/and before the appearance of any specific product and before the effects and impact of its use (or alternative uses) occur. These are ethical issues that can be identified by taking into account the inherent characteristics of that technology, the conditions necessary to achieve it or the generic impact that that technology is likely to have, regardless of how it will be developed in the future. Generic approaches are based on conceptual analysis and empirical observations of the general characteristics of the technology, and sometimes also on projections of the likely future impact resulting from the development and adoption of that technology. An example of a generic approach is the ethical critique of genetic engineering, which argues that genetic manipulation is a play of God because it aims to manipulate the design of new beings brought into the world, which should only be done by God and not by humans. Another example of an approach of this kind is the criticism of an emerging technology because it involves the use of chemicals or physical processes that produce, as a side effect, toxic 
gases or substances. Generic approaches have the advantage over other types of approaches that they do not have to deal with the future developments and uses of a technology, and can be limited only to the analysis of technologies that already exist, thus being able to make statements that involve only to a small extent speculation about the future. On the other hand, the disadvantage of generic approaches is that they can only analyze a small number of ethical problems/dilemmas, namely only those generated by technologies already developed (Brey, 2012, pp.1-13).

A second type of approach is anticipatory or foresight approach that combines ethical analysis with different forecasting methods, forecasting and future study techniques such as trend analysis, scenarios, horizontal scanning, Delphi analysis and other methods of forecasting, forecasting and future study techniques such as trend analysis, scenarios, horizontal scanning, Delphi panels and other methods of studying technology analysis. These techniques are used to forecast future products, services and their potential, likely and plausible uses and to analyze the consequences that may result from the introduction and future developments of the introduction of emerging technologies. The potential ethical problems that may arise with the introduction and development of these technologies are first identified and then morally analyzed, and therefore anticipatory approaches have the unique ability to identify from the very initial, even theoretical, stages, the ethical dilemmas and potential/possible social problems created by the technologies designed to be introduced in the future. Forward-looking ethical analyses try to answer questions such as: It is possible that technology $\mathrm{X}$ allows applications that violate the right to privacy, and therefore it must be developed and introduced in such a way that this risk is minimized. Technology $\mathrm{X}$ can also have military applications that are morally unacceptable, and that is why that technology must be regulated extremely strictly to prevent it from being used for morally unacceptable purposes. Technology X will lead or has the potential to lead to increased socio-economic inequalities, and therefore it must be developed and introduced in a way that takes this moral issue into account. Among the forward-looking approaches are ethical technology assessment (Palm, Hansson, 2006, pp.543-558), anticipatory technology ethics (Brey, 2012, pp.1-13), ethical impact assessment (Wright, 2010, pp.199-226), the ETHIC APPROACH(the ETICA approach) (Stahl, Heersmink, Goujon, Flick, den Hoven, Wakunuma, 2010, pp.20-38), the techno-ethical scenarios approach (Boenink, Swierstra, Stemerding, 2010, pp.1-38), the moral plausibility approach (Lucivero, 2015; Lucivero, Swierstra, Boenink, 2011, pp.129-141), each of which has its own unique strengths (Brey, 2017, p.179). For example, the ethical impact assessment of technology is useful in the case of innovative projects, provided that it can provide a series of recommendations, based on an ethical analysis, useful in the process of implementing the respective technology. Ethical techno scenarios are able, by studying the potential future directions of evolution of the moral sphere, to provide ethical analyses based on possible or potential future values of stakeholders affected by the impact of emerging technologies. Also, forward-looking ethics analysis of technology is probably the only approach that can make full use of the methods and techniques of forecasting and forecasting the technology and can therefore provide a detailed methodology that combines these techniques with ethical analysis. Last but not least, the prospect of moral plausibility provides a series of epistemological tools for critically assessing the plausibility of expectations about the future. The strength of the forward-looking approaches is that they are the only ones capable of a detailed and comprehensive analysis of the possible future and/or potential ethical problems/dilemmas that may be generated by emerging technologies. On the other hand, the weak point is that anticipatory approaches are based on speculative information about a future that is extremely uncertain and, under these circumstances, making solid predictions extremely difficult, very often projections of potential future technological developments and their likely impact being completely erroneous. Because of this, forward-looking analyses tend to be used more successfully in the short-term assessment of developments and the impact of emerging technologies in the near future, a time horizon for which they can generate useful information on potentialities and conditionalities concerning emerging technologies, even if they are not fully predictive. 
Technology is an inherent source of risk because technological artefacts often produce unintended consequences, and a technological environment in a process of change at an extremely rapid pace introduces additional risks due, on the one hand, to the countless social, economic and political opportunities it creates and, on the other hand, because it facilitates the emergence of threats to people and the environment. The acceleration of technology-induced changes creates additional risks resulting from the interaction of multiple technological systems. Some approaches focus on the potential risks that new emerging technologies may pose, including health, safety, economic and environmental risks. These predominantly non-ethical approaches include risk analysis and riskbenefit analysis. Risk analysis is the process of defining, evaluating, analyzing and managing risks (Haimes, 2015) and is usually divided into the risk assessment process, which represents the identification, assessment and measurement of the probability and severity of risks and in the risk management process that represents the decision-making process regarding the potential risks. Riskbenefit analysis is the process of comparing the risks and potential benefits of introducing and/or using new or existing technologies, the purpose of this analysis is to determine the risk-benefit ratio that represents the proportion in which an action is risky in relation to its potential benefits. The principle of this type of analysis is that actions should only be taken if the risk-benefit ratio is supraunitary. These types of analyses are largely quantitative and do not explicitly use ethical assessment criteria, although in recent decades ethical risk analysis has increasingly developed, an approach that introduces ethical criteria into quantitative risk analysis (Asveld \& Roeser, 2009). The ethical analysis of the risk of new emerging technologies involves the identification of potential risks that may arise as a result of the development, introduction and use of these technologies, followed by the moral assessment of these risks and, based on these analyses, the formulation of risk management strategies that are morally justified. Ethical risk analysis and risk-benefit analysis of new emerging technologies are anticipatory approaches, among their strengths being the use of quantitative methods, but on the other hand, as with all anticipatory approaches, they have a number of weaknesses, represented by the fact that they depend on projections of a future characterized by uncertainty and the fact that they are highly focused on narrow analysis of technological risk that excludes other types of consequences potentials that have moral charge.

\section{FURTHER IMPLICATIONS AND CONCLUDING REMARKS}

Given that there is a (relatively) clear distinction between "emerging technologies" and "entrenched technology" the difference between the ethics of emerging technologies and that of entrenched technologies becomes evident, the latter being able to evaluate already existing phenomena and processes, while the ethics of emerging technologies focusing on it is evident in particular on the research and development phase of new technologies in order to analyze and redirect their impact on the basis of ethical arguments and implications. The ethics of emerging technologies is largely focused on the potential problems that can be induced by emerging enabling technologies from which they are expected to generate, on the one hand, waves of innovations in several industries and social sectors and, on the other, to create a multitude of ethical issues during this process. Although stand-alone technologies can in turn generate significant ethical dilemmas, they are often specific to a relatively limited number of products and services and therefore, usually, their impact is relatively easier to analyze from a moral point of view than that of enabling technologies which is much more uncertain. Thus, while the ethics of entrenched technologies can appeal to a wide spectrum of concrete data relevant from the point of view of ethical analysis, the ethics of emerging technologies rely more on speculative data on the likely/possible impact of the development of new technologies, products and processes and their potential uses and combinations on society. However, despite the better epistemic positioning of the ethics of the rooted technologies, in recent decades, against the background of the acceleration of technological development, concerns towards the ethics of emerging technologies have intensified because it has the great advantage over 
the ethics of rooted technologies, namely, the possibility of moral normative intervention in the early stages of innovative processes. Thus, while in the case of entrenched technology already in the texture of society and which have already involved massive investments, frequently in the order of billions of dollars, it is extremely difficult to make fundamental changes in terms of their design, in the case of emerging technologies it is still possible to intervene early in the stages when the technologies are still malleable and there are still options for ways of development and widespread introduction into society. On the other hand, ethicists concerned about the moral assessment of the impact of emerging technologies have a much smaller range of empirical data and have to cope with the significant uncertainty implied by future developments and their impact on society.

\section{REFERENCES}

Asveld, L. \& Roeser, S. (Eds.). (2009). The Ethics of Technological Risk. London: Earthscan Publishers.

Boenink, M., Swierstra, T. \& Stemerding, D. (2010). Anticipating the Interaction Between Technology and Morality: A Scenario Study of Experimenting with Humans in Bionanotechnology, Studies in Ethics, Law, and Technology, 4(2), 1-38.

Brey, P. (2001). Disclosive Computer Ethics, in Spinello, R. A., Tavani, H. T. (eds.). (2001). Readings in Cyberethics. Sudbury, MA: Jones and Bartlett Publishers Inc.

Brey, P. (2012). Anticipating Ethical Issues in Emerging IT. Ethics and Information Technology, 14(4), 305-17.

Brey, P. (2012). Anticipatory Ethics for Emerging Technologies. Nanoethics 6(1): 1-13.

Brey, P. (2017). Ethics of Emerging Technology in Hansson, S. O. (ed.) (2017). The Ethics of Technology. Methods and Approaches. London. New York: Rowman \& Littlefield.

Carroll, A. B. \& Buchholtz, A. K. (2009). Business \& Society. Ethics and Stakeholder Management. $7^{\text {th }}$ Edition. South-Western: Cengage Learning.

Collingridge, D. (1980). The Social Control of Technology. New York: St. Martin's Press.

Committee on Forecasting Future Disruptive Technologies (2010). Persistent Forecasting of Disruptive Technologies. Washington D.C.: The National Academies Press.

Haimes, Y. (2015). Risk Modeling, Assessment, and Management. 4th Edition. Hoboken. New Jersey: Wiley.

Hansson, S. O. (Ed.). (2017). The Ethics of Technology. Methods and Approaches. London. New York: Rowman \& Littlefield.

Harari, Y. N. (2014). Sapiens. A Brief History of Humankind, London: Harvill Secker. Penguin Random House.

Harari, Y. N. (2016). Homo Deus. A Brief History of Tomorrow. London: Harvill Secker. Penguin Random House.

Hockfield, S. (2019). The Age of Living Machines. How Biology Will Build the Next Technology Revolution. New York. London: W.W. Norton \& Company.

Ihte, D. (2002). Bodies of Technology. Minneapolis: University of Minnesota Press.

Latour, B. (2009). A Collective of Humans and Nonhumans: Following Daedalus's Labyrinth in Kaplan, D. M. (ed.). (2009). Readings in the Philosophy of Technology. London: Rowman and Littlefield.

Lucivero, F. (2015). Ethical Assessments of Emerging Technologies: Appraising the Moral Plausibility of Technological Visions. Dordrecht: Springer.

Lucivero, F., Swierstra, T. \& Boenink, M. (2011). Assessing Expectations: Towards a Toolbox for an Ethics of Emerging Technologies. Nanoethics. 5(2), 129-41.

Merriam-Webster Inc. (1983). Webster's Ninth New Collegiate Dictionary. Springfield M A: Merriam Webster Inc. 
Mitcham, C. (1994). Thinking Through Technology. The Path Between Engineering and Philosophy. Chicago: The University of Chicago Press.

Moor, J. H. (1985). What is Computer Ethics? in Metaphilosophy, 16, 4, 269.

Naisbitt, J., Naisbitt, N. \& Phillips, D. (1999). High Tech/High Touch: Technology and Our Search for Meaning. London: Nicholas Brealey Publishing Co.

Naisbitt, J., Naisbitt, N. \& Phillips, D. (2001). High Tech/High Touch: Technology and Our Accelerated Search for Meaning. London: Nicholas Brealey Publishing Co.

Palm, E. \& Hansson, S. O. (2006). The Case for Ethical Technology Assessment (eTA). Technological Forecasting \& Social Change, 73(5), 543-58.

Peterson, M. (2017). The Ethics of Technology. A Geometric Analysis of Five Moral Principles. Oxford: Oxford University Press.

Porter, M. (1990). The Competitive Advantage of Nations. New York: The Free Press. A Division of Simon \& Schuster Inc.

Russell, B. (1945). History of Western Philosophy. London: Routledge.

Sollie, P. (2007). Ethics, Technology Development and Uncertainty: An Outline for Any Future Ethics of Technology. Journal of Information, Communication \& Ethics in Society, 5(4), 293-306.

Sollie, P. \& Duwell, M. (eds.). (2009). Evaluating New Technologies. Methodological Problems for the Ethical Assessment of Technology Developments. Springer Science+Business Media B. V.

Stahl, B., Heersmink, R., Goujon, P., Flick, C., Hoven, J. \& Van den, Wakunuma, K. (2010). Identifying the Ethics of Emerging Information and Communication Technologies: An Essay on Issues, Concepts and Method. International Journal of Technoethics 1(4): 20-38.

The World Book Encyclopedia. (1988). "Technology" in The World Book Encyclopedia. Chicago: World Book Inc.

Verbeek, P. P. (2011). Moralizing Technology: Understanding and Designing the Morality of Things. Chicago: University of Chicago Press.

Wright, D. (2010). A Framework for the Ethical Impact Assessment of Information Technology. Ethics and Information Technology, 13(3), 199-226.

Zuboff, S. (2019). The Age of Surveillance Capitalism. The Fight for a Human Future at the New Frontier of Power. New York: Public Affairs. 